\title{
Temporomandibular disorders and eating disorders: a literature review
}

\author{
As desordens temporomandibulares e os transtornos alimentares: \\ uma revisão de literatura
}

João M. C. N. L. Aroucha, ${ }^{1}$ Rosana C. C. Ximenes,${ }^{2}$ Flávia M. N. Vasconcelos, ${ }^{3}$ Marcele W. Nery, ${ }^{4}$ Everton B. Sougey ${ }^{2}$

\begin{abstract}
Introduction: Temporomandibular disorders (TMD) and eating disorders (ED) affect function and parafunction of the oral cavity and have high rates of medical and psychological comorbidity. However, little is known about the possible associations between them, and few studies have investigated the existence of such associations.

Methods: A search was conducted on the SciELO, LILACS, and PubMed/MEDLINE databases to find relevant articles written in English and Portuguese. Only studies involving human beings were included, and there was no limit for year of publication.

Results and conclusions: There is evidence of the correlation between TMD and ED, but their comorbidity must be better understood. The presence of depressive symptoms is an aggravating factor that must also be taken into account during the diagnosis and treatment of those patients.
\end{abstract}

Keywords: Temporomandibular joint disorders, eating disorders, depression, adolescent.

\section{Resumo}

Introdução: As disfunções temporomandibulares (DTM) e os transtornos alimentares (TA) envolvem a função e a parafunção da cavidade oral e apresentam altos índices de comorbidade médica e psicológica. No entanto, pouco se sabe sobre as possíveis associações entre essas entidades clínicas, e poucos artigos avaliaram a existência de uma relação elas.

Métodos: Uma busca foi realizada nas bases de dados SciELO, LILACS e PubMed/MEDLINE a fim de encontrar artigos relevantes escritos em inglês e português. Apenas estudos envolvendo seres humanos foram incluídos, e não foi estabelecido um limite para ano de publicação.

Resultados e conclusões: Há evidências da correlação entre DTM e TA, mas essa comorbidade precisa ser melhor compreendida. A presença de sintomas depressivos é um fator agravante que também precisa ser levado em consideração durante o diagnóstico e tratamento desses pacientes.

Descritores: Transtornos da articulação temporomandibular, transtornos da alimentação, depressão, adolescente.

\footnotetext{
${ }^{1}$ MSc, Department of Neuropsychiatry, Universidade Federal de Pernambuco (UFPE), Recife, PE, Brazil. ${ }^{2}$ PhD. Professor, Department of Neuropsychiatry, UFPE, Recife, PE, Brazil. ${ }^{3}$ Postdoctoral researcher, Department of Neuropsychiatry, UFPE, Recife, PE, Brazil. ${ }^{4}$ Undergraduate dental student , UFPE, Recife, PE, Brazil. Financial support: Fundação de Amparo à Ciência e Tecnologia do Estado de Pernambuco (FACEPE) and Conselho Nacional de Desenvolvimento Científico e Tecnológico (CNPq).

Submitted Feb 20 2013, accepted for publication Aug 06 2013. No conflicts of interest declared concerning the publication of this article.

Suggested citation: Aroucha JM, Ximenes RC, Vasconcelos FM, Nery MW, Sougey EB. Temporomandibular disorders and eating disorders: a literature review. Trends Psychiatry Psychother. 2014;00(0):11-15. http://dx.doi.org/10.1590/2237-6089-2013-0006 


\section{Introduction}

Temporomandibular disorders (TMD) and eating disorders (ED) involve the functional and parafunctional activities of the oral cavity. Even though the prevalence of these conditions is high in Western society, little is known about their possible associations. ${ }^{1}$ The presence of TMD and ED in a patient should be suspected by health professionals that treat these disorders, as one can aggravate the other and even lead to treatment failure. However, there are relatively few reports of physical impairment, such as food intake difficulties, ${ }^{2}$ in TMD patients, and few studies have investigated the prevalence of ED in patients with TMD or chronic facial pain. ${ }^{3}$

TMD is a generic term for a number of clinical signs and symptoms of the masticatory muscles, the temporomandibular joints (TMJ) and associated structures. ${ }^{4}$ Signs and symptoms of TMD, characterized as musculoskeletal orofacial pain, TMJ pain, of both, have been found in practically all populations under study. ${ }^{5}$

ED is a set of psychosomatic diseases associated with numerous severe physiologic and somatic complications. ${ }^{5}$ They affect young women primarily, and their frequency has been increasing. ${ }^{3}$ In the Western world, anorexia nervosa ( $A N$ ) and bulimia nervosa (BN) are the two main types of ED, particularly among white women. ${ }^{1}$

Orofacial pain may interfere with the daily activities of a patient, and the most common consequences are psychological. ${ }^{6}$ At the same time, psychological issues contribute to the development of both chronic pain and ED. ${ }^{3}$ The coexistence of TMD and ED combined with the presence of depressive symptoms may create a vicious circle in which each condition worsens the effects of the other.

\section{Methods}

An electronic search was conducted using the SciELO, LILACS and PubMed/MEDLINE databases to select relevant studies. Moreover, the references of the selected studies and additional materials in the literature, such as books about the same topic, were hand searched. The search terms were temporomandibular disorder and eating disorders.

The search was restricted to studies written in English or Portuguese. Only studies involving human beings were included, but no limitation was placed on publication year.

\section{Results and discussion}

Sixty-one studies published between 1987 and 2012 were initially retrieved using the search terms and parameters. After examining whether they had data about the presence of signs and symptoms of both TMD and ED, 23 were included.

The analysis of these 23 studies revealed that 15 were based on patient populations, ${ }^{1-3,5-16}$ three dealt with data gathered from community samples, ${ }^{4,17,18}$ three were case reports ${ }^{13,19,20}$ and two were literature reviews. ${ }^{21,22}$ Participant age ranged from three ${ }^{18}$ to $82^{2}$ years. Most studies had samples with more women than men m, $^{2-11}$ or with only women. ${ }^{1,3,13,15,17,19,20}$ Only one study had more men than women, ${ }^{4}$ but the difference was very small.

The Research Diagnostic Criteria for temporomandibular disorders (RDC/TMD) was the only diagnostic instrument used to diagnose TMD in one study ${ }^{2}$; one study followed the RDC/TMD guidelines, but that was not their only criterion for a diagnosis ${ }^{10}$ and another used only the Axis II of the RDC/TMD. ${ }^{17}$ Clinical examination was used in seven studies. $1,5,10,12,13,19,20$ Some studies evaluated only signs and symptoms of TMD. ${ }^{3,4,6,8,9,14,18}$ The Hapak questionnaire ${ }^{3}$ and self-reported forms ${ }^{9}$ were also used. A computerized online TMD diagnostic system was used in two studies. ${ }^{7,11}$

ED diagnoses were retrieved from patient charts in some studies, ${ }^{1,5}$ and the Eating Attitudes Test 26 (EAT26) was used in one study. ${ }^{3}$ Most of the studies evaluated only some symptoms, such as difficulties in food intake, chewing or eating soft or hard foods ${ }^{2,7-20}$; one of them used a Visual Analogue Scale (VAS) to assess the level of difficulty in food intake. ${ }^{2}$

\section{Temporomandibular disorders}

The prevalence of TMD signs and symptoms varied according to the population under study. ${ }^{3}$ Several types of disabilities in daily activities of TMD patients have been evaluated. ${ }^{7}$ These patients may have pain and difficulty in daily activities, ${ }^{6,8-10,17}$ such as pain during mouth opening and difficulty in eating. 2,7-9,11-13,18-20 Orofacial pain resulting from TMD affects social interactions and daily behaviors. ${ }^{21}$

TMD may worsen impairment due to ED. The association of TMD signs and symptoms and the ability to take in food is important to understand the levels of impairment found in patients with TMD. ${ }^{2}$ Although several aspects of jaw dynamics are involved in masticatory movements, studies published before the one conducted by Haketa et al. ${ }^{2}$ were limited to abstract measures of masticatory activities, such as eating hard/soft foods or chewing foods.

Chewing correlates with dysfunction in patients with $\mathrm{TMD},{ }^{14}$ who may reduce mastication to avoid the aggravation of facial pain. ${ }^{15,19}$ They are also likely to reduce their intake of dietary fiber. ${ }^{15}$ Concerns about types of food and food intake behaviors should be taken into account for each TMD subtype in the management of patients with TMD. ${ }^{2}$ 


\section{Eating disorders}

The etiology of ED is not clearly understood because of their nature. ${ }^{23}$ The etiology of AN and BN is multifactorial, and biologic, psychological and sociologic factors contribute to the determinants of these disorders. ${ }^{3}$

The salient features of AN are a relentless pursuit of thinness through dieting and exercise associated with intense fear of gaining weight or becoming fat despite the achievement of a significantly low body weight. ${ }^{24}$ Patients with AN tend to feel fat, even when they are extremely thin, and AN is characterized by the refusal to maintain a minimal normal weight in accordance with age and height, as well as by self-starvation, drastic weight loss and thinness. ${ }^{1,22}$

Individuals with $\mathrm{BN}$ are typically women of normal weight in their teens or early twenties who are very concerned about their shape and weight. ${ }^{24}$ $\mathrm{BN}$ is characterized by dieting, binge eating, and purging by individuals whose body weight is usually normal. ${ }^{22}$ Individuals with BN have repeated episodes of uncontrolled eating (binge eating), which are characterized by an accelerated consumption of large amounts of food within a short period of time, followed by compensatory behaviors, such as vomiting, use of laxatives, diuretics and other medications, fasting and exaggerated sports activity. ${ }^{1,24}$ When not binge eating, individuals with BN markedly restrict their food intake, leading to a vicious cycle of binge eating followed by food restriction in an attempt to compensate for binge eating, which then leads to increased appetite, setting the stage for another episode of binge eating. ${ }^{24}$

Vomiting, a prevalent and potentially destructive symptom of ED, leads to significant dental and medical morbidity. It is accompanied by extreme, sudden and unconventional mouth opening. Apparently the vomiting activity affects both the masticatory muscles and tendons, leading to the development of myofascial symptoms. ${ }^{1}$ Self-induced vomiting, binge eating and duration of the ED could also be factors which promote orofacial pain symptoms. ${ }^{5}$

Binge ED was not formally recognized in the Diagnostic and Statistical Manual of Mental Disorders, 4th edition (DSM-IV), but criteria were provided in an appendix for further study. The hallmark feature of binge $E D$ is the occurrence of recurrent episodes of binge eating in the absence of the inappropriate compensatory behaviors characteristic of individuals with BN. ${ }^{24}$

\section{Temporomandibular disorders and eating disorders}

Recent studies have suggested that there is evidence of the coexistence of symptoms associated with TMD among patients with ED. ${ }^{3}$ There is a significantly higher prevalence of clinical TMD signs and symptoms in patients with ED. ${ }^{5}$

Sensitivity to palpation of the superficial masticatory muscles is greater among individuals with ED than among healthy individuals. ${ }^{1}$ Numerous patients with AN also complain of chronic musculoligamentous pain. ${ }^{3}$ Therefore, the TMD symptoms felt by patients with ED are likely of muscular origin. ${ }^{5}$

Healthcare professionals should ask their patients with ED about facial pain, ${ }^{3}$ as symptoms such as headache and facial pain are significantly more prevalent among patients with ED. ${ }^{5}$

Patients with ED usually have a higher risk of (or tendency for comorbidity with) TMD, associated problems and purging behaviors, such as vomiting. Moreover, binge eating may further increase that risk or comorbidity. ${ }^{5}$ The act of vomiting may be detrimental to the stomatognathic apparatus, and may be classified as a predisposing, initiating, or perpetuating factor of TMD. ${ }^{1}$

Special attention should be paid to those who report purging, binge eating, or both. ${ }^{5}$ Dislocations or subluxations of the condyle caused by extreme, unconventional mouth opening may be consequences of frequent self-triggered vomiting, ${ }^{1,17}$ as the mechanical pressure exerted by frequent self-triggering of vomiting, especially when initiated with the fingers, combs, pins, or other hard objects, may lead to damage similar to that sustained during intubations for general anesthesia. ${ }^{25}$

\section{Temporomandibular disorders, eating disorders, and depressive symptoms}

The comorbid occurrence of TMD, ED and depression may complicate and perpetuate the entire symptom complex. ${ }^{3}$ Depression is a common characteristic among individuals with TMD, ${ }^{17}$ and several studies have reported moderate to severe depression in patients with TMD. 7,11

Various psychological signs and symptoms are comorbid with TMD, ${ }^{26}$ and the rates of psychopathologies among patients with TMD are above the average for the general population. ${ }^{27}$ Studies have found a significant association between emotional status and pain while eating or opening the mouth. ${ }^{18}$ Patients with moderate to severe depression had significantly greater mandibular function limitations than normal patients. ${ }^{11}$

ED, in general, are also associated with serious psychological complications. ${ }^{28}$ Patients with ED have significantly greater emotional and psychological distress than patients without ED, ${ }^{1}$ and both $A N$ and $\mathrm{BN}$ are associated with high rates of medical and psychiatric comorbidity. ${ }^{3}$

Adolescents with disordered eating attitudes, potential precursors to ED, seem to have certain psychosocial characteristics, which differentiate them from those with 
healthier eating attitudes. ${ }^{23}$ Patients with chronic ED may be more susceptible to pronounced emotional and psychological stress than healthy individuals. ${ }^{1}$

\section{Temporomandibular disorders, eating disorders, and depressive symptoms in women}

Interest in gender differences in health has been growing, but more studies should investigate specific female health issues. Dental clinicians should be aware that some women may have gender-specific oral health characteristics. ${ }^{22}$ Compared with women without TMD, women with this disorder present with pain of greater intensity, teeth clenching, trouble sleeping, sensitivity to pain in the masticatory and neck muscles, lower quality of life, ${ }^{29}$ higher general muscle sensitivity to palpation and higher emotional and psychological distress. ${ }^{1}$

The incidence of TMD among women is about twice that found among men. The prevalence of women seeking treatment for TMD is even higher, at a 4:1 ratio. ${ }^{22} \mathrm{~A}$ sign that these disorders have a higher incidence among women is the fact that the samples of most studies have more women than men,,$^{2,5-9,11,15,17}$ or that some samples and case reports include only women. ${ }^{1,3,13,19,20,29}$

The prevalence of TMD, ED and depressive symptoms (DS) is higher among women, and the possible comorbidity of these disorders is a fact that stresses the need of a multidisciplinary approach, so that women receive a more holistic and comprehensive treatment. ${ }^{22}$

\section{Diagnosis and treatment}

Ideally, when a patient presents with any of the disorders described above, the presence of the others should be investigated. In the case of TMD, a single symptom or sign of the masticatory system is not synonymous with TMD; nor does it automatically lead to a TMD diagnosis. The use of indices, such as the RDC/ TMD, provides data for more complex associations, as their value is based on multiple variables. ${ }^{1}$

The presence of psychological conditions should be identified early in the management of TMD, as failure to do so may lead to treatment failure and worsening of the patient's condition. ${ }^{1}$ At the same time, if TMD signs and symptoms, such as facial pain, are not diagnosed and treated, they may negatively affect the treatment of ED. ${ }^{3}$

Associated signs and symptoms of TMD and orofacial pain are significantly more common in patients with ED than in those without it. ${ }^{5}$ TMD pain may impair dietary intake, and the health of patients with ED and TMD may be, therefore, further compromised. ${ }^{16}$ Therefore, during the treatment of patients with TMD, the types of food and food intake behavior should be taken into account for each TMD subtype. ${ }^{2}$
Patients with ED should also be examined to detect orofacial pain and associated signs and symptoms of TMD. ${ }^{5}$ Dentists are often the first health professionals to recognize relevant signs of ED because of the oral signs of these disorders. Therefore, dentists should be familiar with those signs and symptoms and their possible consequences during the evaluation and treatment of patients with TMD, and should refer them to a multidisciplinary team. ${ }^{1,30,31}$

Facial pain may have a negative effect on the treatment of ED. Therefore, the treatment of patients with chronic facial pain may have implications for the treatment of people with ED. The presence of depression may have practical implications in the treatment of these populations, and a patient that has both disorders should be treated by a multidisciplinary team. ${ }^{3}$

Further studies should be conducted to better understand the possible comorbidity between TMD and ED. ${ }^{1,3}$ Ideally, clinical examinations should be included in future studies of this association. ${ }^{3}$ TMD should not be diagnosed using signs and symptoms alone, but also using indices, such as the RDC/DTM. ${ }^{1}$

\section{Conclusions}

There is evidence of the correlation between TMD and ED, but this comorbidity should be better understood. The presence of depressive symptoms is an aggravating factor that should also be taken into account during diagnosis and treatment. Some of the gaps in the understanding of those disorders may be the result of their analysis as separate conditions when, in fact, they may be comorbid in some patients.

\section{References}

1. Emodi-Perlman A, Yoffe T, Rosenberg N, Eli I, Alter Z, Winocur E. Prevalence of psychologic, dental, and temporomandibular signs and symptoms among chronic eating disorders patients: a comparative control study. J Orofac Pain. 2008;22:201-8.

2. Haketa $T$, Kino K, Sugisaki M, Amemori $Y$, Ishikawa $T$, Shibuya $T$, et al. Difficulty of food intake in patients with temporomandibular disorders. Int J Prosthodont. 2006;19:266-70.

3. Goldberg MB, Katzman DK, Woodside DB, Baker GI. Do eating disorders and chronic facial pain coexist? A preliminary study. J Can Dent Assoc. 2006;72:51.

4. Thilander B, Rubio G, Pena L, de Mayorga C. Prevalence of temporomandibular dysfunction and its association with malocclusion in children and adolescents: an epidemiologic study related to specified stages of dental development. Angle Orthod. 2002; $72: 146-54$

5. Johansson AK, Johansson A, Unell L, Norring C, Carlsson GE. Eating disorders and signs and symptoms of temporomandibular disorders: a matched case-control study. Swed Dent J. 2010;34:139-47

6. Segù M, Lobbia S, Canale C, Collesano V. Quality of life in patients with temporomandibular disorders. Minerva Stomatol. 2003; 52:279-87.

7. Yap AU, Chua EK, Hoe JK. Clinical TMD, pain-related disability and psychological status of TMD patients. J Oral Rehabil. 2002;29:374-80.

8. Voog U, Alstergren $\mathrm{P}$, Leibur $\mathrm{E}$, Kallikorm R, Kopp S. Impact 
of temporomandibular joint pain on activities of daily living in patients with rheumatoid arthritis. Acta Odontol Scand. 2003;61:278-82.

9. Karibe H, Goddard G, Kawakami T, Aoyagi K, Rudd P, McNeill C. Comparison of subjective symptoms among three diagnostic subgroups of adolescents with temporomandibular disorders. Int J Paediatr Dent. 2010;20:458-65.

10. Karibe H, Goddard G, McNeill C, Shih ST. Comparison of patients with orofacial pain of different diagnostic categories. Cranio. 2011;29:138-43.

11. Yap AU, Tan KB, Hoe JK, Yap RH, Jaffar J. On-line computerized diagnosis of pain-related disability and psychological status of TMD patients: a pilot study. J Oral Rehabil. 2001;28:78-87.

12. Tallents RH, Macher DJ, Kyrkanides S, Katzberg RW, Moss ME. Prevalence of missing posterior teeth and intraarticula temporomandibular disorders. J Prosthet Dent. 2002;87:45-50.

13. Sasaguri K, Ishizaki-Takeuchi R, Kuramae S, Tanaka EM, Sakurai T, Sato $\mathrm{S}$. The temporomandibular joint in a rheumatoid arthritis patient after orthodontic treatment. Angle Orthod. 2009;79:804-11.

14. Kurita H, Ohtsuka A, Kurashina K, Kopp S. Chewing ability as a parameter for evaluating the disability of patients with temporomandibular disorders. J Oral Rehabil. 2001;28:463-5.

15. Raphael KG, Marbach JJ, Touger-Decker R. Dietary fiber intake in patients with myofascial face pain. J Orofac Pain. 2002;16:39-47.

16. Irving J, Wood GD, Hackett AF. Does temporomandibular disorde pain dysfunction syndrome affect dietary intake? Dent Update. 1999;26:405-7.

17. Rodrigues JH, Biasotto-Gonzalez DA, Bussadori SK, MesquitaFerrari RA, Fernandes KP, Tenis $\mathrm{CA}$, et al. Signs and symptoms of temporomandibular disorders and their impact on psychosocial status in non-patient university student's population. Physiother Res Int. 2012;17:21-8.

18. Alamoudi N. Correlation between oral parafunction and temporomandibular disorders and emotional status among Saudi children. J Clin Pediatr Dent. 2001;26:71-80.

19. Braun BL. Treatment of an acute anterior disk displacement in the temporomandibular joint. A case report. Phys Ther. 1987; 67:1234-6.

20. Kaku M, Koseki H, Kawazoe A, Abedini S, Kojima S, Motokawa M, et al. Treatment of a case of skeletal class II malocclusion with temporomandibular joint disorder using miniscrew anchorage. Cranio. 2011;29:155-63.
21. Hollister MC, Weintraub JA. The association of oral status with systemic health, quality of life, and economic productivity. J Dent Educ. 1993;57:901-12.

22. Zitzmann NU, Schilling J, Weiger R, Pastoret $M H$, Loretan P. Genderspecific dental health issues and treatment considerations. Int J Prosthodont. 2007;20:360-8.

23. Costarelli V, Antonopoulou K, Mavrovounioti Ch. Psychosocial characteristics in relation to disordered eating attitudes in Greek adolescents. Eur Eat Disord Rev. 2011;19:322-30.

24. Walsh BT. The importance of eating behavior in eating disorders. Physiol Behav. 2011;104:525-9.

25. Okeson JP. Bell's Orofacial Pains. 6th ed. Chicago: Quintessence; 2005.

26. Lindroth JE, Schmidt JE, Carlson CR. A comparison between masticatory muscle pain patients and intracapsular pain patients on behavioral and psychosocial domains. J Orofac Pain. 2002;16:277-83.

27. Gatchel RJ, Garofalo JP, Ellis E, Holt C. Major psychological disorders in acute and chronic TMD: an initial examination. J Am Dent Assoc. 1996;127:1365-70.

28. Katzman DK, Zipursky RB, Lambe EK, Mikulis DJ. A longitudinal magnetic resonance imaging study of brain changes in adolescents with anorexia nervosa. Arch Pediatr Adolesc Med. 1997;151:793-7.

29. Moreno BG, Maluf SA, Marques AP, Crivello-Júnior O. Avaliação clínica e da qualidade de vida de indivíduos com disfunção temporomandibular. Rev Bras Fisioter. 2009;13:210-4.

30. Ximenes R, Couto G, Sougey E. Eating disorders in adolescents and their repercussions in oral health. Int J Eat Disord. 2010;43:59-64.

31. Ximenes RC, Colares V, Bertulino T, Couto GB, Sougey EB. Versão brasileira do "BITE" para uso em adolescentes. Arq Bras Psicol. 2011;63:52-63.

\section{Correspondence:}

João Marcílio Coelho Netto Lins Aroucha

Rua Maria Carolina, 560, Boa Viagem

51020-220 - Recife, PE - Brazil

Tel./Fax: +55 (81) 3463.8892 / +55 (81) 9521.1942

E-mail: joaoaroucha@gmail.com 